ERR A T UM

Elisabeth M. Hodson • Jonathan C. Craig •

Narelle S. Willis

\title{
Evidence-based management of steroid-sensitive nephrotic syndrome
}

Published online: 4 February 2006

(C) IPNA 2006

\section{Pediatr Nephrol (2005) 20:1523-1530}

The review erroneously listed references 12,28 and 30 under "Anonymous" rather than "Arbeitsgemeinschaft für Pädiatrische Nephrologie".

The online version of the original article can be found at http:// dx.doi.org/10.1007/s00467-005-1968-8

E. M. Hodson ( $)$ J J. C. Craig · N. S. Willis

Cochrane Renal Group,

NHMRC Centre for Clinical Research Excellence in Renal

Medicine, Centre for Kidney Research,

The Children's Hospital at Westmead,

Locked Bag 4001, NSW 2145 Westmead, Australia

e-mail: Elisah@chw.edu.au

Tel.: +61-2-98453430

Fax: +61-2-98453432

E. M. Hodson · J. C. Craig

School of Public Health,

University of Sydney,

Sydney, Australia 